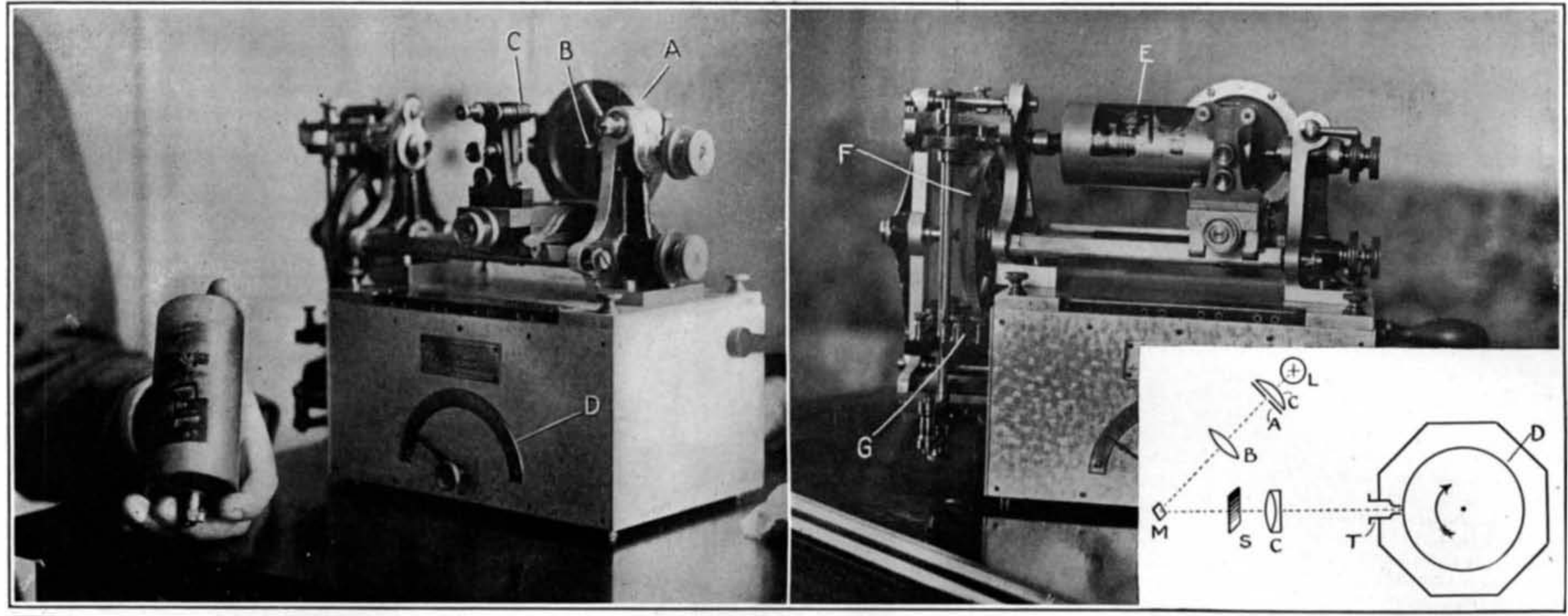

Two views of the transmitting device for sending photographs, manuscript, drawings, and printed matter over wires and (in the insert) the method employed for

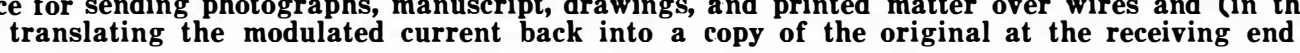

\title{
Sending Photographs Over Wires
}

\section{Details of the Belin System To Be Tried Between St. Louis and New York}

\section{By Austin C. Lescarboura}

THE important happening in Shanghai is printed in 1 the New York newspapers the following morning. Indeed, so remarkable is our news-gathering machinery of today that half the world knows precisely what the other half is doing by the telegraphed or cabled or via radio word. And in due course the first half receives photographs of the happening in the second half of the world, thus completing the account; for if there is one thing certain in modern journalism, it is that photo graphs tell a story incomparably better and more readily than the best word picture.

Now, then, were it possible to transmit the story and the photographs simultaneously, our news-gathering machinery would be nearly perfect. Many a fine photograph must needs be discarded for the reason that it tograph must needs be discarded for the reason that it metropolitan newspapers. There is a tremendous wastmetropolitan newspapers. There is a tremendous wast-
age in this direction, due to the weeks and even months age in this direction, due to the week
which must elapse in transmission.

which must elapse in transmission. With the urgent need for a rapid means of to the efforts of M. Edouard Belin of Paris, France, with a greater sense of appreciation. M. Belin has been working on the problem of transmitting photographs over wires since 1907 . After certain changes in his basic designs as well as constant refinement in all the details, he has finally achieved noteworthy results for his latest system. In fact, he has to his credit the transmission of photographs over telegraph lines between Paris and Lyons, Paris and Bordeaux, Paris and Nice, Paris and London, and Paris and Antwerp.

At present M. Belin and his assistants are in the United States for the purpose of demonstrating the telestereograph, as it is called, over long-distance lines. The first test is to be between St. Louis and New York, and is being conducted under the auspices of the $S t$. Louis Post-Dispatch and the Now York World. It may be that M. Belin will later attempt the transmission of photographs between New York and San Francisco; but at any rate, he has come to this country of vast distances in order to put his system to the acid test, so to speak.

The first attempts at telegraphic transmission of autographical texts go back to the work of Abbé Caselli in 1860 and the device known as the Pantelegraph Caselli. The first attempts at the transmission of photography are attributed to the German, Professor Korn of Munich, who made use of selenium but later on, in a modified system, returned to a scheme very similar to that of Caselli. In the case of M. Belin the selenium and other delicate elements have been replaced by more practical means. The transmission is simply a matter of preparing a bas relief of the photograph, and then tracing that bas-relief with a stylus connected to a telephone transmitter. The latter varies the current flowing over the telegraph or telephone line in accordance with the relative height of any point on the bas relief record at any given moment. At the receiving end this current variation is translated into various gradations of light in the manner described further on.

The first step, then, is to prepare the transmitting record or plate. A copper cylinder forms the base of the record, and its surface is coated with a 5 per cent shellac solution. Meanwhile a carbon print is made in the conventional photographic manner from the photographic negative to be transmitted, after which the print is wrapped face to face with the shellacked copper cylinder. The cylinder with the print is then placed in hot water, with the result that the gelatine

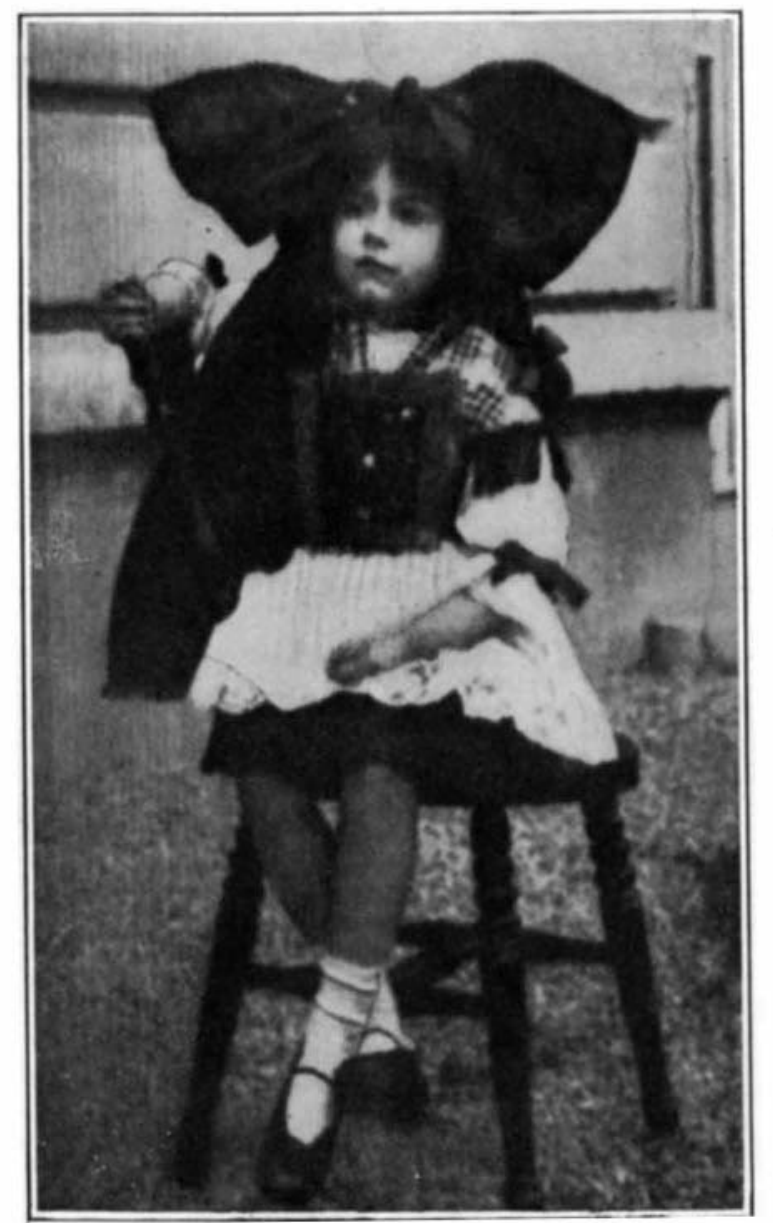

Reproduction from a photograph received by $M$.
Belin's apparatus. Note that in our half-tone reproduction considerable detail is lost of the print adheres to the cylinder in accordance with its own degree of blackness, while the unexposed gelatine is washed away with the paper. In this manner a coating of uneven thickness is formed on the cylinder, or a photograph in bas-relief.

The copper cylinder is then placed in the transmitting device which bears a close resemblance to the cylinder type phonograph. As will be noted in the two illus trations of the same transmitter at the bead of this account, the components of the transmitter are: $A-\mathbf{A}$ special microphone with a stylus $B$, which is in constant contact with the face of the cylinder. $C$ is another form of stylus, about which we shall have more to say further on. $D$ is a speed regulator, controlling the clockwork which drives the transmitter $E$ is the copper cylinder with the photograph in bas-relief. The cylinder, it will be noted, can be inserted or removed with as much ease as the changing of cylinger records on the phonograph. $F$ is a two-speed gear transmissiun. driving the cylinder. $G$ is the synchronizer, which causes the receiver to keep in step with the transmitte by a series of electrical impulses sent over the line.

As the copper cylinder revolves, the microphone, with its stylus always in contact with the record face, is slowly moved along the record, touching practically every part of its surface. As the unevenness of the surface depresses the microphone stylus more or less, the current flowing through the microphone is modulated so as to correspond with the varying density of the photograph.

The receiving end must translate these electrical variations back into the original photographic terms. This it does in the manner indicated in the line drawing which forms the insert of the two illustrations at the head of this account. First of all, we have a special form of diminutive arc light shown at $L$, vhich sends its rays through the condenser $C$ and the aperture $A$ and again through the lens $B$ on to a tiny mirror M. The mirror is mounted on the twin wires of a Blondel oscillograph-an apparatus with powerful Blondel oscillograph-an apparatus with powerful electro-magnets and a pair of silver wires which carry
the oscillating mirror, located in the powerful magnetic the oscillating mirror, located in the powerful magnetic
field. The Blondel oscillograph is a highly sensitive apparatus, and the immersion of the wires in thick oil causes the action to be practically "dead beat," or, to put it in another way, the wires have little momentun. As the current of varying intensity comes over the wires to the receiving set, the wires of the Blondel oscillograph cause the tiny mirror to turn more or less on its axis However, no matter how far the mirror may turn, its reflected beam still passes through the screen $S$, the lens $C$, the almost microscopic aperture at $T$ and on to the sensitized surface on the cylinder $D$.

The whole crux of this apparatus is the screen $S$ which is a screen of varying transparency. That is to (Continued on page 483) 


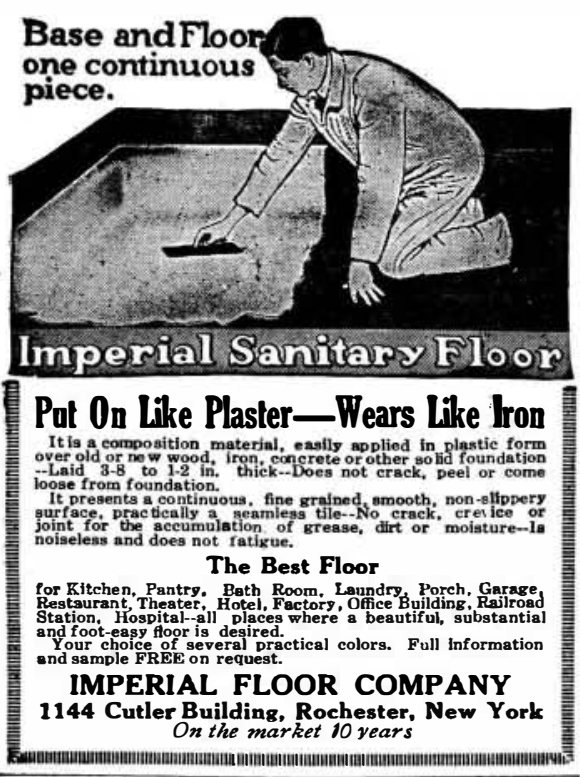

THE 100\% WIRELESS
MAGAZINE

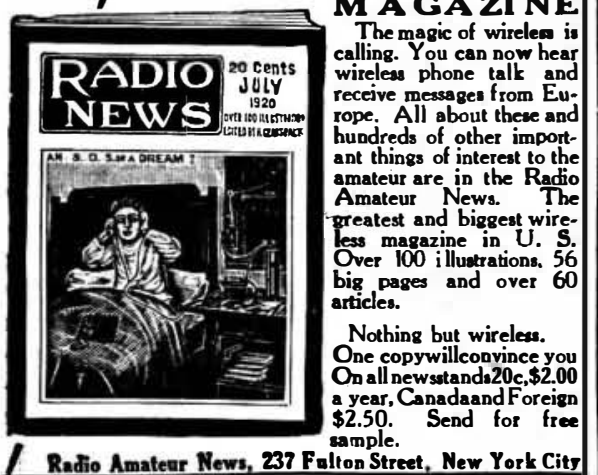

$\angle$ Radio Amateur News, 237 Fulton Street, New York City
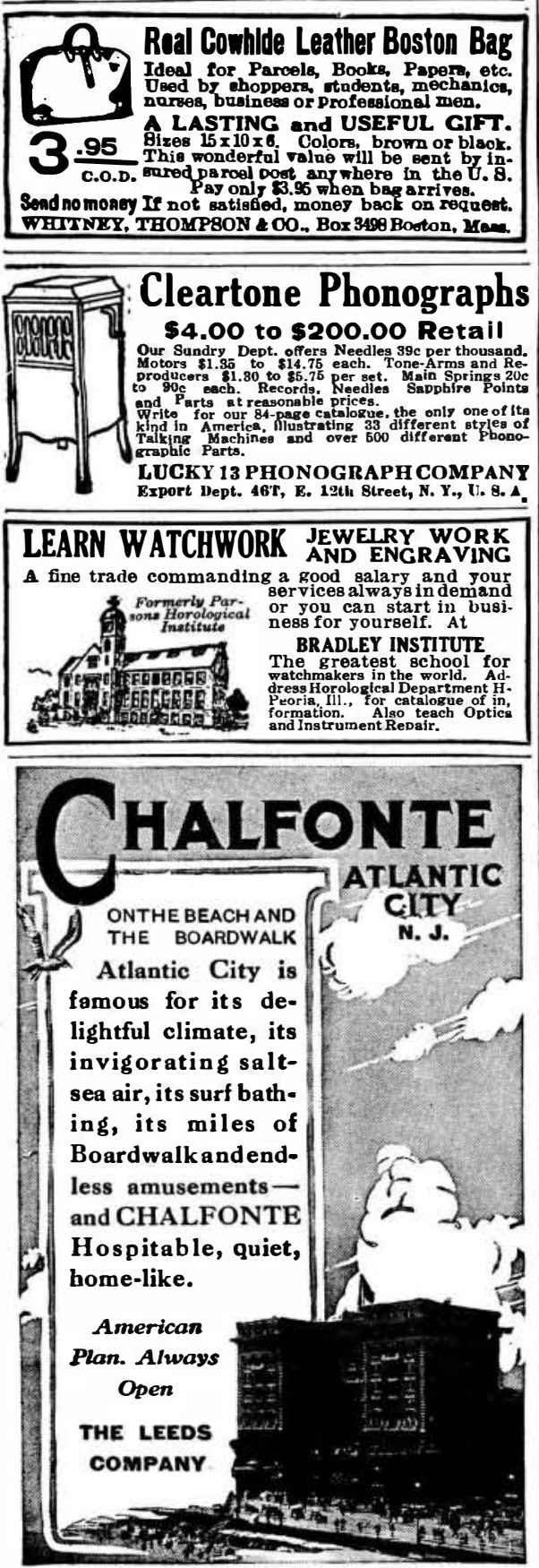

Sending Photographs Over Wires (Continued from page 4\%4)

say, at one end it is absolutely opaque, but going toward the other end it becomes steadily more transparent until it reaches practical transparency. Thus the stylus attached to the microphone at the transmitting end is at a given moment on a black or high spot of the cylinder, and and this heavy current at the receiving end causes the mirror to be so pointed that the beam of refiected light strikes the opaque end of the finely graduated screen and thus fails to make an impression on the sensitized receiving cylinder. In this case the receiving cylinder will receive an impression and using it as a photographic negative any number of positive prints can be made. It also follows that if the graduated screen is reversed, or if the polarity of the Blondel oscillograph is reversed, the receiving cylinder can be made a photographic positive.

So much for the general details, but there are numerous refinements, as might well be imagined, in an apparatus capable of accomplishing such delicate work. The aperture through which the beam of light passes on to the receiving cylinder is of microscopic proportions and is made in a silver disk which presses against the recording surface. This hole is of a size corresponding to the pitch of the feed mechanism, so that the light record, made in the form of a continuous spiral, has its threads so close together that it forms to all intents and purposes a solid photowould exposure. Otherwise the spiral turns, which would destroy the usefulness of the received photograph.

Obviously, the transmitter and receiver must operate in step or in perfect synchronism, otherwise serious distortion results. To this end a special device is used at the transmitting end, for the purpose of starting the cylinders at both ends at the same time. When one cylinder gets a little ahead of the other, a special arrangement causes its retardation until the other cylinder has caught up so to speak. This feature of the system comprises speial contact members and solenoids.

The cylinder of the receiving apparatus can take a piece of film or a strip of sensitized paper, and the emulsion of either can be of such speed as to take care of the rate of operation. The cylinder is contained in a metallic case of octagonal shape, the loading of same being accomplished in a dark room. By means of a number of cylinders and containers, the receiver is operated in a manner quite suggestive of the conventional camera and plate-holders

Regarding the rate of transmission which is obviously an all-important factor when the main arteries of the world's communication system are to be leased for the purpose of transmitting photographs, M. Belin tells us that this is a question of quality and fineness of detail. Some photographs are not so detailed as others, hence the transmission can be done on a somewhat coarser scale. And even the finely detailed photograph can be transmitted at a faster rate if it is permissible that the copy at the receiving end be of coarser quality. Detailed photographs can be faithfully transmitted in from four to eight minutes each, while coarser photographs or those which require rapid transmission can be handled in three to six minutes. Belin hopes for even more rapid transmission in the near fuure.

Something has been said about another contact-making device, indicated by $C$ in one of our photographs. This device is intended for the transmission of matter in straight black-and-white, as distinguishe from the half-tone graduation of photographs. In this case a given piece of writing, type matter or drawing is transferred on to the copper cylinder with the aid of a special ink, thus leaving a raise impression after drying. The contact-

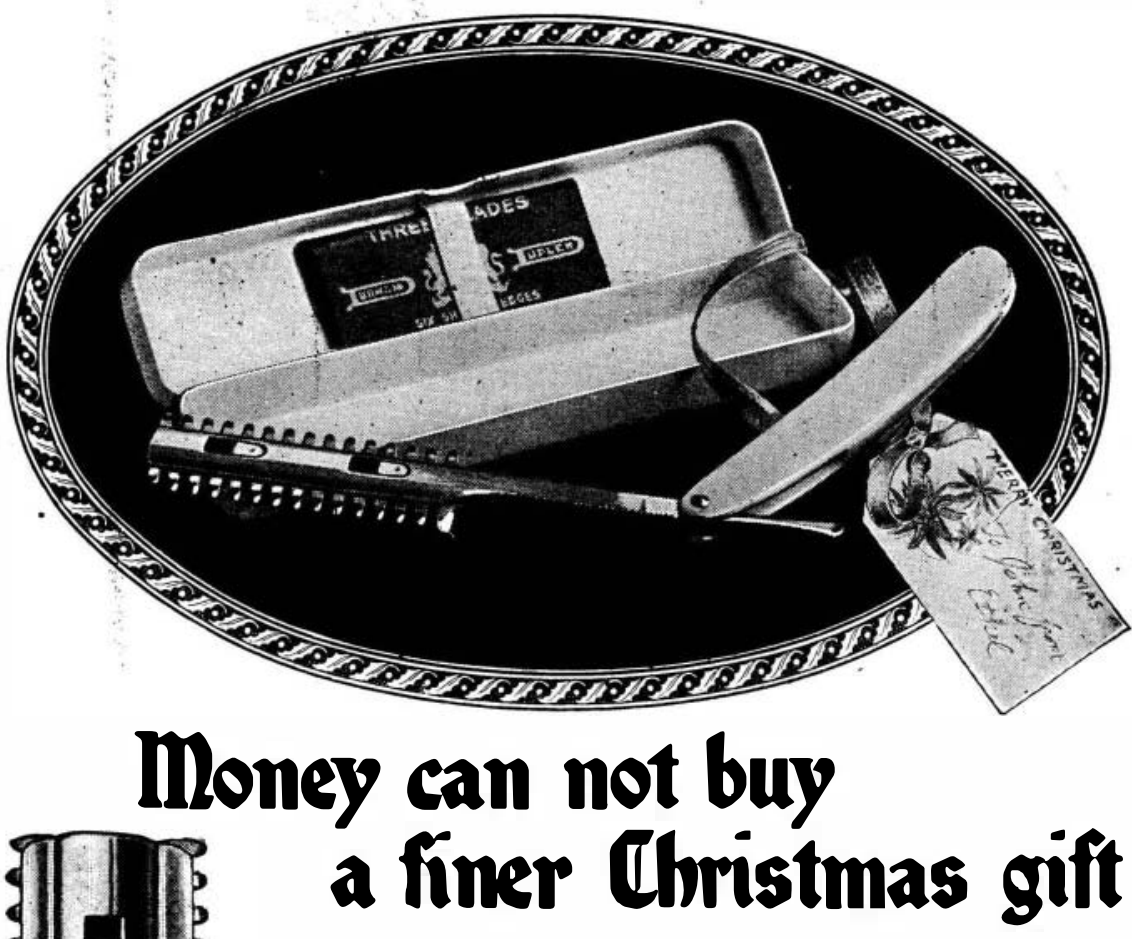

NO matter how much you spend, you can not find a handsomer, more useful, more acceptable gift for "him" than a Durham-Duplex Razor at One Dollar. Packed in an attractive case of American ivory, with three double-edged, hollow-ground, oil-tempered Durham-Duplex blades, famous for their wonderful sharpness, this beautifully finished razor is sure to bring a smile of genuine appreciation on Christmas morning.

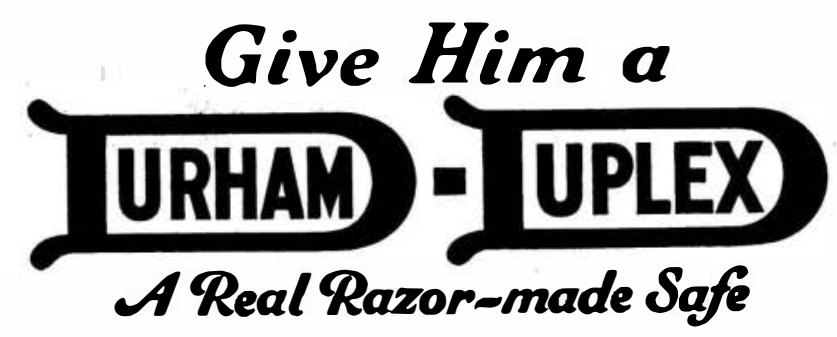

Standard Set, as described above, One Dollar. Special Christmas Model, with gold plated blade holder and safety guard, Two Dollars. Other Sets up to $\$ 12$

Additional Blades

50 Cents for a Package of 5 DURHAM DUPLEX RAZOR CO. Jersey City, New Jersey JERSEY CITY, U.S.A. SHEFFIELD, ENG.
PARIS, FRANCE
TORONTO, CANADA
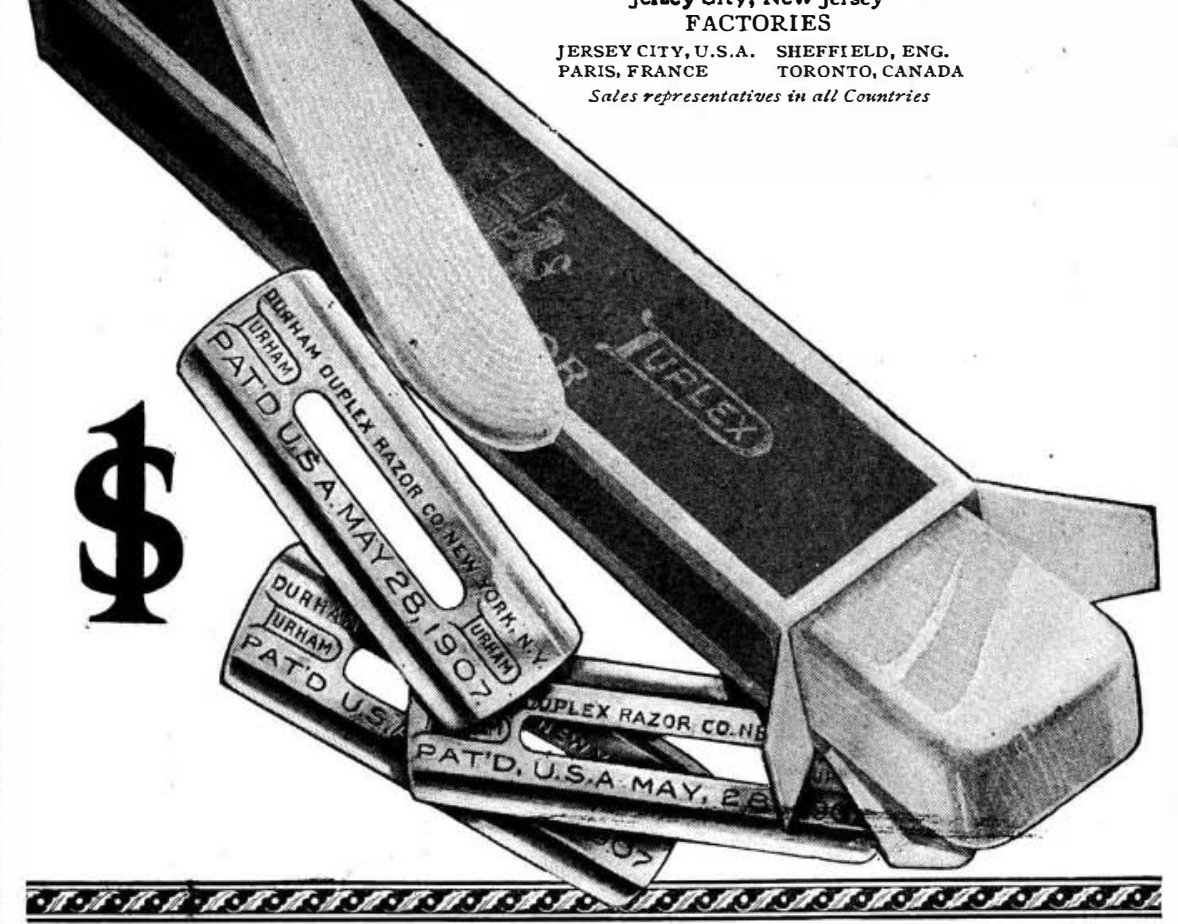


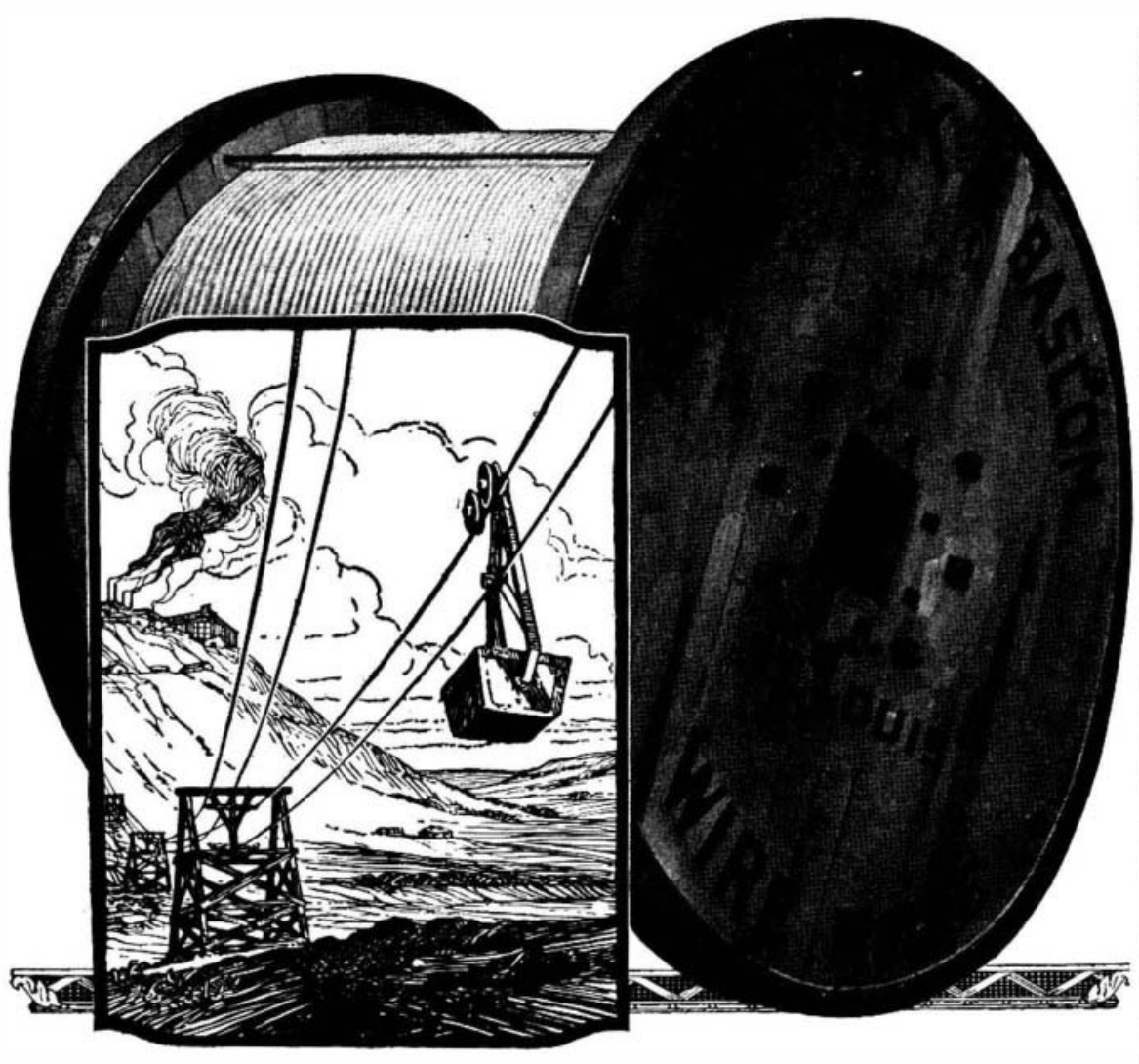

Aerial Transportation

Overhead, out of the way of ordinary traffic, the conveyor of the Aerial Wire Rope Tramway makes regular trips between loading and unloading stations, unaffected by mud, ice, sleet or snow.

This form of transportation, so economical under certain conditions, was not practical until the manufacture of wire

Now, Aerial Wire Rope Tramways are used very generally in transporting coal, ore, logs, rock, sand and many other materials from where they are to where they are wanted.
Their scope, already broad, has been Their scope, already broad, has been greatly extended by
high cost of labor.

high cost of labor.
In addition to being pioneers in the manufacture of wire rope, for many
years the Broderick \& Bascom Rope

Co. has designed Aerial Wire- Rope Tramways of every type, and erected them in practically every part of this country, in Canada, Alaska and Mexico. Much of their success has been due to the efficiency of the Broderick \& Bascom track cables were equipped.

There is a grade of Broderick \& Bascom Wire Rope best suited to every purpose. Our YELLOW STRAND, distinguished by having one strand painted yellow, is not excelled in strength a
ity by any other rope

BRODERICK \& BASCOM ROPE CO., ST. LOUIS, MO.

Factories: St. Louis and Seattle. Branches: New York and Seattle. Warehouses: St. Louis, New York, Seattle.
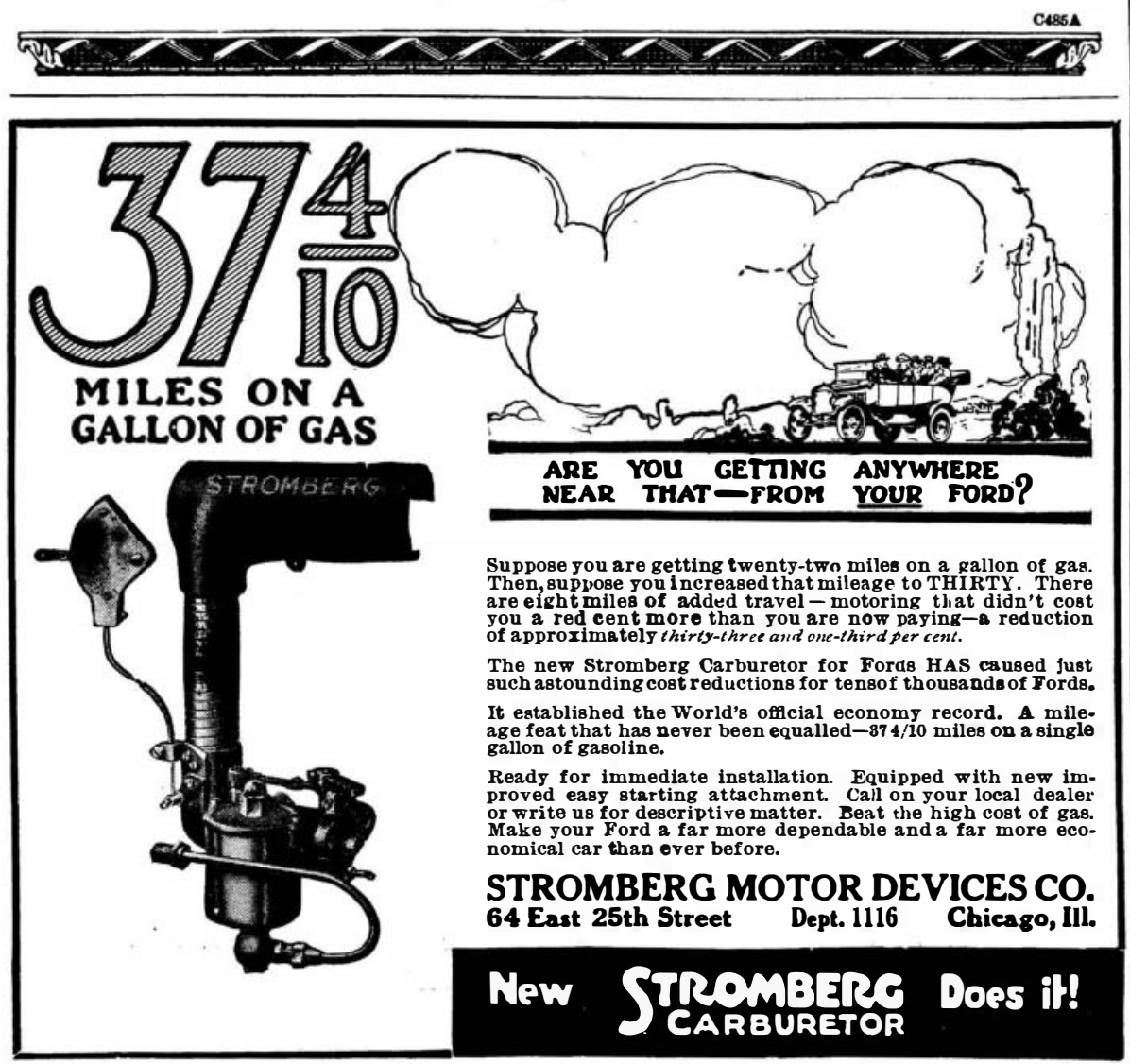

break device actuated by its stylus press- using a patented process for combining ing against and in constant contact materials used in bitulithic paving, and with the copper cylinder. $\quad$ machinery used in connection with laying At the receiving end the graduated such material, held covered by the conscreen is replaced by an opaque screen tractor's bond conditioned on contractor's which has a single vertical slit. This ar- payment for materials furnished for the rangement means that the mirror has only two positions so far as the sensitized receiving drum is concerned, namely, shining through the slip and on to the sensitized surface, or striking the opaque plate and thus making no impression on the sensitized surface. In this manner straight black-and-white matter can be transmitted at a high rate of speed and the reproduction must necessarily be quite the reproduction must necessarily be quite
faithful. M. Belin told the writer that he had transmitted cartoons, manuscrip and type matter with excellent results. Photographic proofs of printed or other matter measuring four by six inches can be transmitted in four to eight minutes, and $\mathbf{M}$. Belin has under construction machines which will assure the transmission of 10,000 words of text in printed form per hour.

Aside from its application to modern journalism, which is obviously the main purpose to which all electro-photographic transmission systems can be put, there are other uses. One which suggests itself to us is in the transmission of police photoSuch a use would prove invaluable in the running down of criminals. Then there is a distinct legal use for such a system, in the transmission of facsimile evidence, signatures, and so on. There is also a military use. Perhaps, too, the sysanyone to transmit photographs over telegraph and telephone wires to distant friends, although it would seem that the cost of such messages must remain quite high for a long time to come

The same system can be applied to radio, by coupling the Belin apparatus with the usual arc, high-frequency alternator, vacuum tube or other type of continuous-wave transmitter. All in all, this system is applicable wherever wires or the transmission of human thoughts.

\section{Recent Patent Decisions}

(Continued from page fir6)

away with the annoying tintinnabulations, is entitled to protection, where the specifications disclose the method, even though the inventor is ignorant of the scientific principles involved.

Where a person, by anything which he does or says, or abstains from doing or saying, when it is his duty to act or speak in respect of a subject matter, intentionally causes or permits another person to believe a thing to be true, and to would have acted but for that belief and he so acts, and materially changes his position in respect of the matter to his detriment, then the first person is not
allowed, in a suit between himself and allowed, in a suit between himself and such other person, to deny the truth of the thing done or stated. Also, delay in prosecuting other infringers while the validity of a patent is in active litigation does not constitute laches or negligence. -Searchlight Horn Co. v. Victor 'I'alking MCh. Co. U. S. D. C. of N. J.

Patents Used by Contractor.-This is an appeal to the Court of Last Resort of Arizona, and the decision and opinion of the Supreme Court of Arizona touches upon a matter involving patent law. The case was one brought by sureties on bonds against a street cleaning contractor concerning a series of controversies involving many issues.

It is held that a patentee or owner of a patent has the right to charge a reasonaa patented material or process, and that without procuring from the patentee or owner of a patent the right to use the patented material or process there can be no lawful use thereof. Royalties due
from a contractor for the privilege of improvement. That the owner of a patent process did not file agreement to furnish all the material and give license to use of patents at definite price as required by specifications did not preclude or's surety for royalties due where the price was reasonable and neither the city nor property owners objected.-U. S. Fidelity \& Guar. Co. v. Calif.-Ariz. Const. Co. et al. Supreme Court of Ariz.

Eliminating the Flash From Rifles and Big Guns

THE production of smokeless powder 1 at once rendered the art of locating the enemy's batteries comparatively difficult. However, such location often remained possible at night because of the flash observed upon the firing of the gun. A French scientist, M. Delpech, now proposes to suppress these telltale flashes, and his report upon the matter was not long ago laid before the French Academy of Sciences.

The ball of flame which is formed at the mouth of the gun is a result of the masses of carbon monoxide and of methane, which take fire upon coming into contact with the air, where they form a detonating mixture with the oxyzen of the latter, whereupon a second explosion produces the luminous flash. If experiments be made with a "75" gun for example, with different powders, it will be seen that the fiash of light is always produced with powders that employ at a high temperature of combustion, while with powder employing a lower temperature of combustion the flash is diminished in intensity. When a naval "75" which is longer, is desired, the gases are not ignited, since they are too much cooled by their passage through the longer barrel. In the same manner it is found that the same gun cartridge will produce a flash or not produce it according to whethe the barrel of the rifle is short or long. These observations at once suggest the method by which the flash may be suppressed-in one way or another the gases must be cooled. One way of doing this is by adding, to the charge of powder, salts which contain water of crystallization and therefore exert an anti-thermic plished, on the other hand, by physical plished, on the other hand, by physical Delpech has demonstrated that the flash can be extinguished by the addition of 20 grams of vaseline to the charge of powder. In certain kinds of guns it is sufficient, indeed, merely to apply a plentiful coating of grease to the projectile. No change either in the pressures or in the speed of projection takes place but the flash is extinguished.

The suppression of the flash is more difficult in the case of big guns, because the mass of gas formed is so enormous. But it can be successfully accomplished, according to this investigator, by greasing the entire surface of the cartridges with grease or vaseline (20 per cent of the weight of the powder). These flameless powders were first obtained in 1917 , and have given entire satisfaction ever since the time when at M. Delpech's sug gestion the diminution in the liberation of heat was compensated by a corresponding increase in the weight of the powder (4 ained by introducing 2 per cent of vaseline into the powder. The suppression of the flame is complete with the guns experimented upon. The vaseline in no way modifies the firing action, the pressure and the rate of speed remaining unaltered; furthermore, the vaseline is ound to exert a powerful stabilizing action upon B powder.-By M. Tevis. 
From Coal Barge to Ship's Bunker

A COAL barge with an elevator and chute has made A its appearance in San Francisco Bay and has as a purpose the direct coaling of a ship while the cargo is being unloaded, obviating the necessity of the ship's proceeding to a bunker wharf to receive its fuel. Instead of the usual clam-shell bucket, such as is used at bunker wharves, the coal is sent up on an elevator and bunker wharves, the coal is sent up on an elevator and on board operates the elevator.

\section{Converting Steel Back Into Iron}

CONSIDERABLE has been said and written about making steel in the electric furnace, which is a development of the last four years. Not so much has been promulgated about making pig iron from steel in such a furnace. It is standard practice to make pig iron, from which all steel is originally made, by smelting iron ore in a blast furnace and thus reducing or converting it to metallic iron, so-called, in the shape of pig iron.

A new and unique method has recently been developed however for converting scrap or old steel back into pig iron. Why this is done or even is necessary needs explanation first. At times certain kinds of pig iron are hard to obtain as made by standard methods. This has been true lately in Canada and France. It was therefore necessary to make it by a new method if possible.

The illustration shows how this was and is done in France. It represents a French electric furnace for converting scrap steel back into pig iron, something never thought possible nor probable only two or three years ago. Scrap steel or borings or turnings are charged from the upper flat form into the top of the furnace shown. Electricity is conducted into this furnace by the apparatus suspended from the wall. When the crude steel is melted certain additions are made to it so as to increase the percentage of carbon, silicon, etc., and very soon after the mass is tapped out at the bottom, as shown, in the shape of pig iron. It can be seen flowing into systematic molds made in a bed of sand. When cold it is removed and is called "pig" iron because each section of iron is attached to the central larger section or trough much as pigs gain their sustenance from the mother sow.

Many tons of such iron has been made in both France and Canada and it is regarded as, or can be made, the finest pig iron of any.

\section{The Motorcycle's Future}

former British and German motorcar Nowner has to be content with the more modest motorcycle, we may look for a considerable development along the lines of general utility and cheapness, says a writer in a British technical review.

Before the war the tendency of the motorcycle, under American influence, was towards increased weight and horse-power, and consequent complexity. Now, however, the chief considerations are safety, lightness, and simplicity to meet the requirements of the average man, who wants a cycle that will start up without causing him undue exertion, that can be lifted up and down steps and is not prohibitive in price or upkeep.

The lines on which improvements should proceed are, above all, toward simplification and comfort. The belt drive, a fruitful cause of breakdown, must be eliminated, the various parts simplified and their number reduced, the lighting system should be made as elementary as possible, and all complicated control on

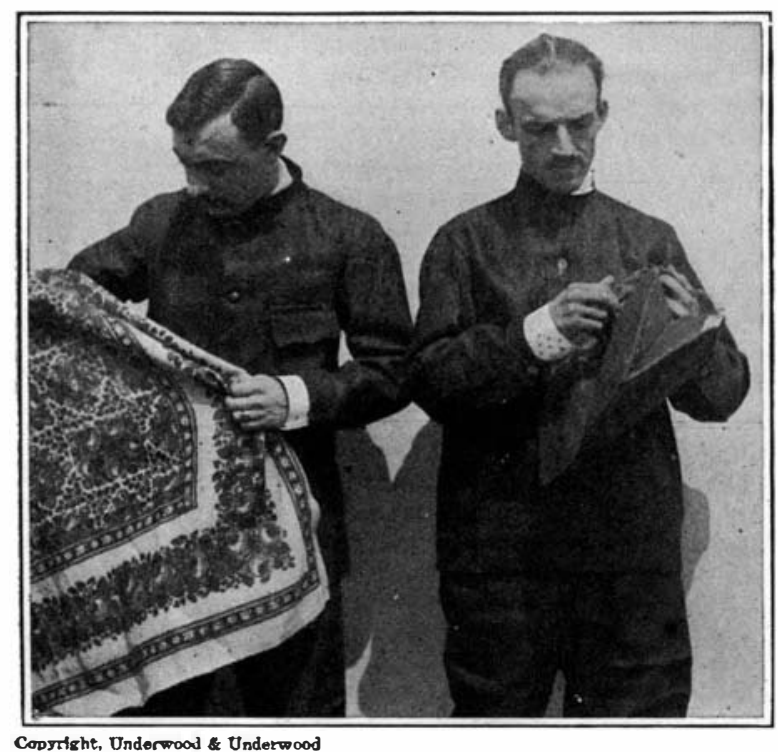

Austrian suits for workmen, a damask luncheon cloth and a laundry bag-all made of paper

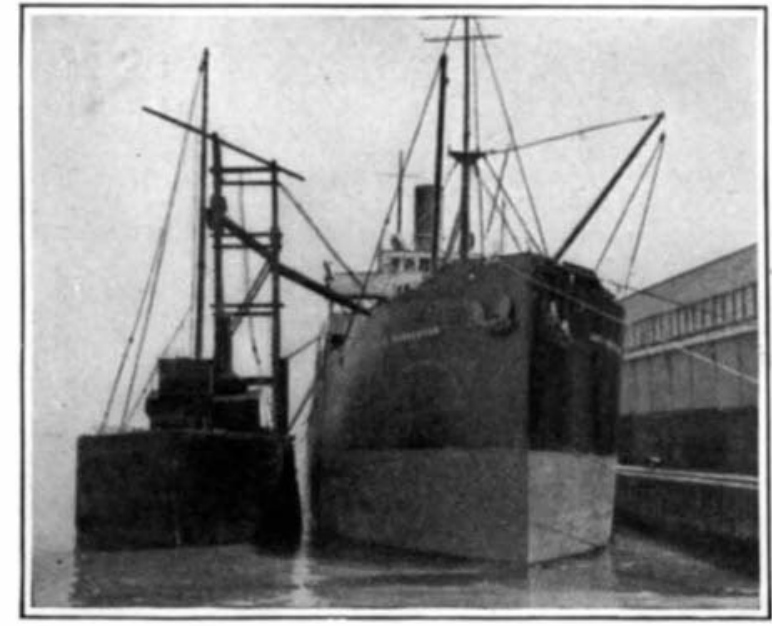

This coal barge delivers its coal directly to the chip by means of an elevator and chute

the handle-bars suppressed. Special care must be given to the brakes and the saddle should be made adjustable to the rider's comfort.

Another paramount necessity is that wheels should be made easily removable, in view of rendering the repair of punctured tires as simple a matter as possible, and there is plenty of scope for improvement in the

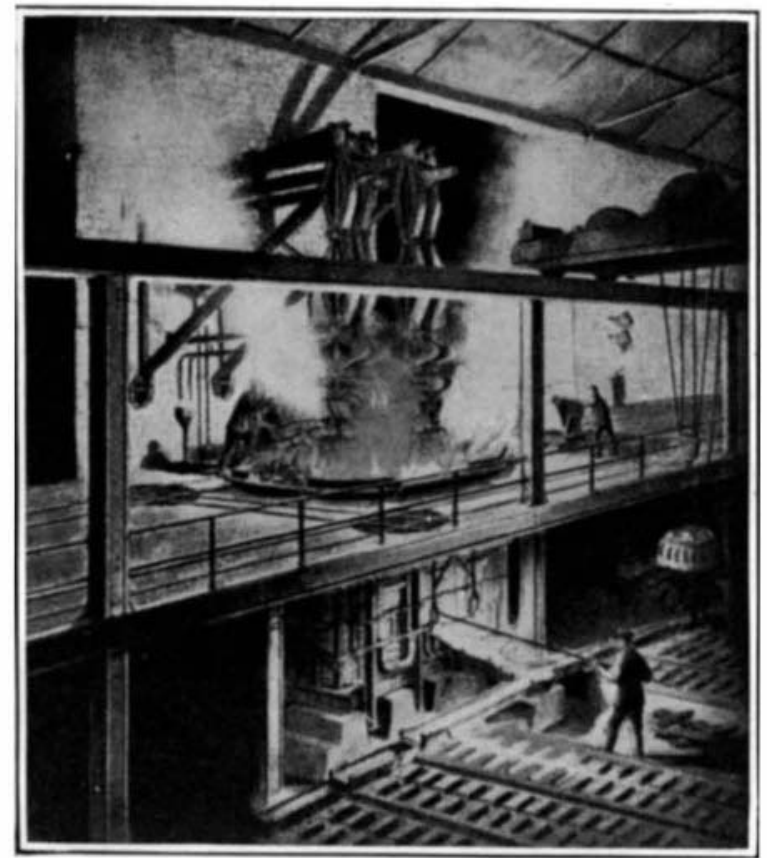

An electric furnace used in France for the purpose of converting scrap steel back into pig iron

tires themselves. High speed is not required, therefore the engine can and should be as light as is compatible with reliability. The development of the motorcycle as the plain man's vehicle also promises a future for the autowheel and motorscooter.

\section{Shall We Wear Paper Clothes?}

$B$ EFORE we part with a good share of our yearly income for a serge or woolen suit, it may be a matte of real wisdom to look into the paper clothes situation. It any rate, the Bureau of Foreign and Domestic Commerce has on exhibition a large assortment of Austrian paper clothing and associated paper articles collected for the information of the American clothing and other interested industries. The exhibit includes workmen's suits, table covers, collar and cuffs, laundry bag, wall decoration, twine and other articles.

In this interesting collection there is a suit made of 40 per cent paper, which sells in Austria for 575 crowns, or about $\$ 2.65$ in American money at the present rate of exchange. A workman's all-paper suit in brown is quoted at 32 crowns, or about 15 cents in American money. A hlue all-paper suit is more expensive, 120 crowns (about 55 cents) being the asking price

The report which accompanies the paper samples states that the garments are really washable, cold water, soap, and a scrubbing brush being the proper means. It is also reported that during the past year Austrian paper goods manufacturers have exported large quantities of their output to I taly and to Turkey. A previous report spoke of about 40,000 German paper suits being on display in a store on the Strand, London. After a brief stay in the Bureau of Foreign and Domestic Commerce, the paper articles will be offered to clothing and other interested manufacturers for examination.
A Grass Lawn Like a Carpet

$\mathrm{T}$ is proverbially a slow business getting a good 1 grass lawn in a garden, but a new English idea makes it possible to secure a fine stretch of verdure just as one would buy a carpet at the stores. Grass seed is sown thickly on strong canvas and, when this is thickly covered with growth it is ready for making the lawn. The site is well prepared, being made perfectly level and special attention is given to getting the soil so that it is a farorable rooting medium for the little plants. Then the grass mats are put down on sections, these being closely fitted together. As time goes on the roots push down through the canvas and, in this way, establish a permanent lawn. Ultimately the material will rot. The value of this plan lies in the fact that an immediate effect can be secured. It is quite easy to have a splendid grass lawn in a situation where, a few hours before, there was nothing of the kind. From thenceforward the grass will go on improving and the little plants speedily take a hold on the soil.

\section{A New Kind of Coal}

HERE is a new suggestion as to fuel-a new kind he coal. It is especially timely with coal at the high prices at present obtaining. The idea comes from a plant and is the result of experiments carried out in Greaker, Norway, where an improved prohas been employed to produce sulfite coal as a byproduct from the manufacture of wood pulp.

A ton of wood pulp yields 9 to 10 cubic meters of sulfite lye, of which 95 per cent is available for the production of coal, compared with about 60 per cent from other processes. If the new process is generally adopted it is estimated that it will be possible to produce annually sulfite coal equivalent to 800,000 tons of imported coal.

Considerable quantities of cheap alcohol are preduced from the wood pulp lye before it is made into coal. An essential feature of the new process is high concentration of the lye before removal from the autoclaves. By concentrating it to 30 per cent not only is a high percentage of coal-producing substance obtained, but the quantity of solid matter is increased by 50 and even 70 per cent.

\section{A Fountain for the Cows}

CHE average dairy cow drinks anywhere from 60 to 100 pounds or more of water daily-in fact unless she gets plenty to drink, her milk yield will be visibly reduced. That is why dairy farmers devote particular attention to equipping their farms with all the modern facilities-somewhat in the nature of dairy cow soda fountains-for satisfying Bossie's thirst.

One eastern farm has provided durable concrete water tanks in each field where the cows are paslured. The tanks are connected directly with the farm water supply, a float being placed in each tank so that the water level is maintained at the same point ali the time. Considerable trouble obtained due to the fact that the cows would nose and damage the floats so that they would not work properly. Then the owner devised the type of tank shown in the accompanying picture which provides a sort of square-shaped nub at one side of the tank for the float and the inlet and overflow pipes. An iron framework is provided over the top of the compartment so that the cows cannot reach or touch the fluat with their noses. Now Bossie and her mates never lack for fresh water as the dairy never runs dry.

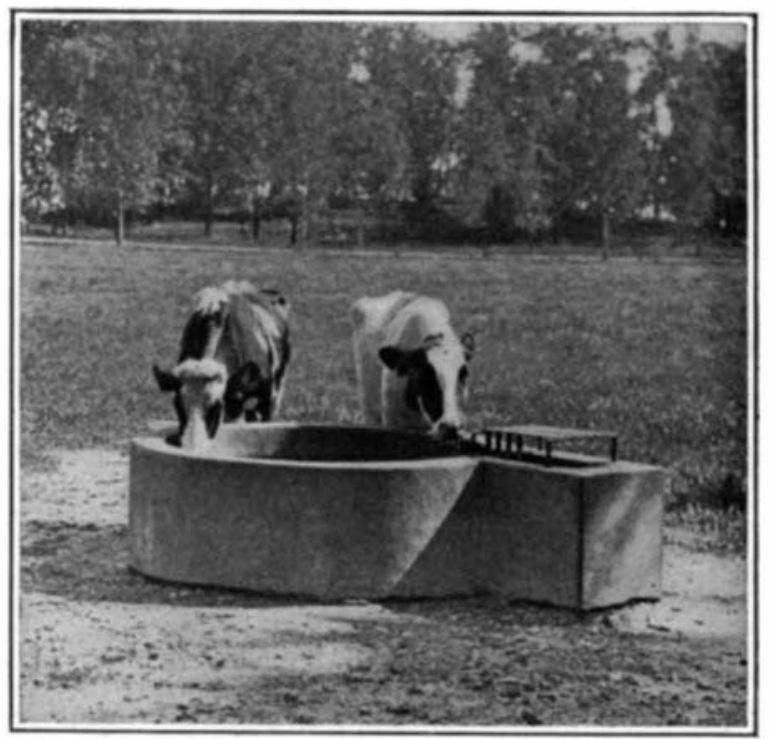

This concrete fountain serves fresh water to herd of cows without attention of any kind 